\title{
Coleta e preparação de pêlos de mamíferos para identificação em microscopia óptica
}

\author{
Juliana Quadros ${ }^{1} \&$ Emygdio L. de A. Monteiro-Filho ${ }^{2}$
}

\author{
1 Rua Piraí do Sul 51. Vila São José, Augusta. 81290-170 Curitiba, Paraná, Brasil. \\ 2 Departamento de Zoologia, Setor de Ciências Biológicas, Universidade Federal do Paraná. Caixa Postal 19020, \\ 81531-980 Curitiba, Paraná, Brasil.
}

\begin{abstract}
Collecting and preparing mammal hairs for identification with optical microscopy. Hair microstructure is a useful tool to identify mammals and is applied in several disciplines such as forensic sciences, ecology, epidemiology, arqueology and paleontology. The methods applied to collect and prepare mammal hairs to identify them under the optical microscopy are many and range from the most cheap and rapid to the most expensive and laborious. The present study aims to test different methods to collect, clean and prepare mammal hairs for cuticular and medullar patterns observation under optical microscopy, to compare these methods to the literature and to describe in detail a new suggested method. To prepare the reference collection, hairs were collected from the back of identified museum specimens with known collecting localities. Cuticular impressions were obtained pressing hairs against a thin nail varnish layer let dry for 15 to 20 minutes on glass slides. In order to observe the medullar pattern, hairs were submitted to diafanization with comercial oxigenated water 30 volumes for 80 minutes. Permanent glass slides were mounted with Entellan and temporary ones with glicerin. The advantages of this method are the easy aquisition and handling of the material and the practical execution, enabling its use in the field.
\end{abstract}

KEY WORDS. Diet; ecology; mastozoology; taxidermy; tricology.

RESUMO. A microestrutura dos pêlos é uma ferramenta útil na identificação das espécies de mamíferos e é aplicada a várias disciplinas como ciências forenses, ecologia, epidemiologia, arqueologia e paleontologia. Os métodos aplicados na coleta e preparo de pêlos de mamíferos para sua identificação em microscopia óptica são numerosos e variam dos mais baratos e rápidos aos mais caros e laboriosos. $O$ presente estudo tem por objetivos testar diferentes métodos de coleta, limpeza e preparo de pêlos de mamíferos para observação dos padrões cuticular e medular em microscopia óptica, comparar estes métodos com a literatura e descrever em detalhe um novo método recomendado. Para preparar a coleção de referência, os pêlos foram coletados do dorso de espécimes com localidade de coleta conhecida e coligidos em acervos museológicos. Impressões cuticulares foram obtidas pressionando os pêlos contra uma fina camada de esmalte para unhas incolor colocada sobre uma lâmina de vidro e seca por 15 a 20 minutos. Para observar o padrão medular, os pêlos foram submetidos a diafanização em água oxigenada comercial 30 volumes por 80 minutos. Lâminas permanentes foram montadas com Entellan e lâminas temporárias com glicerina. As vantagens desse método foram a fácil aquisição e manuseio do material e a prática execução, permitindo seu uso durante trabalhos de campo.

PALAVRAS CHAVE. Dieta; ecologia; mastozoologia; taxidermia; tricologia.

No estudo da microestrutura dos pêlos de mamíferos são empregados métodos para observação do padrão cuticular, medular e da forma do corte transversal (TEERINK 1991). A maioria dos métodos utilizados na visualização da cutícula em microscopia óptica tem por objetivo obter uma impressão da superfície do pêlo (escamas cuticulares) sobre uma camada de um meio plástico ou gelatinoso (Williamson 1951, KhmelevskaYa 1965, Carter \& Dillworth 1971, Weingart 1973 Twigg 1975, Din \& Stenson 1982, Petrarco 1986, Charvet \& Keller 1989, Teerink 1991, Oli 1993). Fazem exceção a essa regra, Koonz \& Stradine
(1945) e DaGnall et al. (1995), que utilizaram um corante para dar contraste e permitir a visualização das escamas cuticulares no próprio pêlo, assim como Bowyer \& CURRY (1982), que utilizaram a impressão do pêlo sobre tiras de acetato aquecidas. Por outro lado, os procedimentos de preparo dos pêlos para visualização da medula em microscopia óptica são menos numerosos (Charvet \& Keller 1989, TeErink 1991) e consistem, basicamente, no clareamento opcional do pêlo em água oxigenada amoniacada ou em hidróxido de potássio e sua montagem temporária ou permanente em lâmina e lamínula. De forma geral, 
os métodos referenciados anteriormente consistem de etapas de difícil execução prática e necessitam de reagentes e equipamentos caros e/ou de difícil aquisição.

Os objetivos do presente trabalho são testar métodos de coleta, limpeza e preparação de pêlos de mamíferos para observação do padrão cuticular e medular em microscopia óptica, compará-los com outros métodos descritos na literatura e propor um método eficiente e prático, descrevendo-o detalhadamente.

\section{MATERIAL E MÉTODOS}

Todos os procedimentos descritos a seguir foram realizados com espécies de mamíferos selecionadas pelas características de seus pêlos-guarda (comprimento, espessura e cor) e pela disponibilidade de material, almejando uma ampla diversidade de morfotipos.

Assim, para os testes e comparação dos métodos foram utilizados pêlos-guarda de Dasypus novemcinctus Linnaeus, 1758 (Xenarthra), Sturnira lilium (E. Geoffroy, 1810) (Chiroptera), Cebus apella (Linnaeus, 1758) (Primates), Cerdocyon thous (Linnaeus, 1766), Pseudalopex gymnocercus (G. Fischer, 1814), P. vetulus (Lund, 1842), Eira barbara (Linnaeus, 1758), Nasua nasua (Linnaeus, 1766) (Carnivora), Tayassu pecari (Link, 1795), Pecari tajacu Linnaeus, 1758 (Artiodactyla) e Akodon spp. Meyen, 1833 (Rodentia). Na etapa de elaboração de lâminas para visualização da medula, os pêlos das espécies supracitadas e também de Didelphis spp. Linnaeus, 1758 (Didelphimorphia), Panthera onca (Linnaeus, 1758), Puma concolor (Linnaeus, 1771), Leopardus spp. Gray, 1842, Oncifelis spp. Severtzov, 1858, Herpailurus yaguarondi (Lacépède, 1809) (Carnivora), Mazama spp. Rafinesque, 1817 (Artiodactyla), Hydrochaeris hydrochaeris (Linnaeus, 1766), Agouti paca (Linnaeus, 1766) (Rodentia), Sylvilagus brasiliensis (Linnaeus, 1758) e Lepus europaeus Pallas, 1778 (Lagomorpha) foram empregados. Foram realizadas três repetições para cada espécie e cada método.

\section{Coleta das amostras de pêlos}

Foram comparados quatro métodos de coleta de pêlos de animais vivos e tombados em coleções científicas: arrancar um tufo de pêlos da pelagem do mamífero com auxílio de uma pinça, arrancar o tufo com os dedos, cortar o tufo com auxílio de uma lâmina de bisturi e cortar o tufo com auxílio de uma tesoura. Após a coleta, todas as amostras de pêlos foram embaladas em envelopes de papel pequenos, rotulados com o método, a numeração de coleta e a espécie de mamífero.

\section{Limpeza dos pêlos}

Os pêlos foram submetidos a dois métodos de limpeza: lavagem em uma solução de éter sulfúrico e álcool etílico (1:1) (SHORT 1978) e lavagem em álcool etílico comercial puro (adaptado de Charvet \& Keller 1989). Em seguida, nos dois protocolos de limpeza, os pêlos foram secos em papel absorvente através da ação mecânica de passar os pêlos no papel no sentido do bulbo para o ápice, com auxílio de uma pinça de ponta fina. Como controle foram montadas lâminas com pêlos não lavados.

\section{Preparação de lâminas de impressões cuticulares}

Os métodos para observação da cutícula comparados nesse trabalho envolvem a impressão da superfície do pêlo (cutícula) sobre uma fina camada de um meio aplicado sobre lâmina de vidro previamente limpa, variando: 1) o meio utilizado para revestimento da lâmina, 2) o tempo de secagem do meio e 3) o instrumento utilizado na compressão do pêlo sobre o revestimento da lâmina. Para testar a utilização de diferentes métodos nessas três etapas foram realizados os seguintes procedimentos: lâminas foram revestidas com uma delgada camada de esmalte para unhas incolor (aplicada com auxílio do pincel próprio da embalagem do produto) ou com um esfregaço de cola branca escolar produzido a partir de uma gota de cola espalhada com auxílio de uma lamínula. Nos dois tipos de meio de revestimento utilizados, as lâminas foram secadas por 5, 15, 30 e 60 minutos. Depois destes tempos de secagem dos meios, os pêlos foram colocados sobre o revestimento das lâminas. Cada lâmina, agora contendo os pêlos, foi colocada sobre um pedaço de madeira com largura e comprimento aproximados aos de uma lâmina e espessura de 1 $\mathrm{cm}$ e coberta por outro pedaço de madeira idêntico ao anterior mas revestido por várias camadas de fita adesiva lisa, transparente e larga para que as fibras da madeira também não ficassem impressas sobre o esmalte. Estes "sanduíches" formados pela lâmina, com os pêlos, entre os dois pedaços de madeira foram comprimidos de duas maneiras diferentes: através de um grampo em "C" ou "sargento", como os utilizados em marcenaria; e através de uma morsa, prensa ou torno de mesa com braços retangulares de dimensões aproximadas às de uma lâmina. Depois da compressão, os "sanduíches" foram abertos e as lâminas cuidadosamente removidas da madeira de cobertura. Nesse momento, os pêlos encontravam-se aderidos ao meio de revestimento da lâmina, o qual foi deixado secar completamente por pelo menos 30 minutos. Só então os pêlos foram retirados através de duas maneiras: passando gentilmente a ponta do dedo seca e limpa sobre os pêlos ou tocando com uma pinça de ponta fina na porção do escudo dos pêlos, até que se descolassem. As lâminas de impressões cuticulares foram acondicionadas dentro de caixas portalâminas de madeira protegidas da poeira e observadas em microscópio óptico nos aumentos de 100, 200 e 400 vezes.

\section{Preparação de lâminas para observação da medula}

Foram comparados métodos de confecção de lâminas para observação da medula dos pêlos os quais variaram de acordo com (1) a substância diafanizadora dos pêlos, (2) os tempos de diafanização, (3) o efeito da realização de cortes transversais no escudo dos pêlos sobre a diafanização e (4) o meio de montagem das lâminas permanentes. Para testar a eficiência de diferentes métodos nas quatro etapas citadas acima foram utilizados os seguintes protocolos: pêlos foram embebidos em água oxigenada comercial 30 volumes, solução de hidróxido de potássio em água a $2 \%$ ou solução de hipoclorito de sódio em água a 90\% para diafanização. Os tempos de permanência nos agentes diafanizadores testados foram 10, 20, 40, 60, 80, 120 e 180 minutos. Adicionalmente, para o agente diafanizador água 
oxigenada comercial 30 volumes e o tempo de diafanização de 80 minutos, foi testada a realização de cortes transversais, com uma tesoura pequena de ponta fina, no escudo dos pêlos mais espessos, como os de Didelphis spp., Cebus apella, Tayassu pecari, Pecari tajacu, Hydrochaeris hydrochaeris, Agouti paca, Sylvilagus brasiliensis e para as espécies de carnívoros. O número de cortes transversais feitos, um a três, foi uma função do comprimento do escudo. Em qualquer um dos protocolos acima citados, após a diafanização, os pêlos foram lavados em água e secos com papel absorvente. Em seguida foram montadas lâminas permanentes e temporárias. Na montagem de lâminas permanentes foram utilizados Bálsamo do Canadá Sintético ou Entellan e na montagem de lâminas temporárias, utilizou-se água ou glicerina sempre coberta por lamínula. As lâminas para visualização da medula foram rotuladas e observadas em microscópio óptico nos aumentos de 100, 200 e 400x, mas apenas as lâminas permanentes foram acondicionadas em caixas porta-lâminas de madeira. Para comparação, o protocolo controle dos agentes diafanizadores, tempos de ação dos agentes e realização de cortes transversais, foi feito através da preparação de lâminas com pêlos não diafanizados e inteiros.

\section{RESULTADOS E DISCUSSÃO}

\section{Coleta das amostras de pêlos}

Sempre que a coleta de amostras de pêlos foi feita com o auxílio de um objeto cortante (tesoura ou lâmina de bisturi) os pêlos foram danificados deixando de possuir o bulbo e uma parte da haste, além do risco associado de cortar a pele do espécime. Nos casos em que os pêlos foram coletados com pinça a análise microscópica mostrou que possuíam escoriações em sua superfície e muitos pêlos foram arrancados sem bulbo. Por outro lado, quando os pêlos foram arrancados com os dedos esse risco foi suprimido e na maioria das amostras os pêlos possuíam bulbo e haste. Os trabalhos sobre identificação microscópica de pêlos usualmente não fornecem detalhes sobre os procedimentos utilizados na coleta dos pêlos, mas é consenso entre os autores que os pêlos analisados devem estar inteiros e que a haste é particularmente importante na caracterização do padrão das escamas cuticulares (TeERINK 1991). Nesse sentido, o método de coleta de pêlos que consiste em arrancá-los com os dedos mostrou-se mais adequado que os demais testados.

\section{Limpeza dos pêlos}

Não foi possível detectar diferenças nos resultados obtidos através dos dois agentes de limpeza dos pêlos, os quais foram igualmente positivos em relação aos controles não lavados. Nesse sentido, a opção pelo álcool etílico comercial foi feita com base na facilidade de compra e manipulação do produto em relação ao éter sulfúrico e álcool etílico (1:1). Os pêlos de $D$. novemcinctus exigiram maiores cuidados durante o processo de limpeza, o que possivelmente está relacionado ao hábito de vida semifossorial da espécie, sendo necessária a ação mecânica de limpeza passando o pêlo molhado em álcool pelo papel absorvente várias vezes para que fossem obtidos melho- res resultados. Outros métodos recomendados freqüentemente na bibliografia são, a lavagem em água morna com detergente (TeErink 1991) e o uso de tetracloreto de carbono (Williamson 1951, Carter \& Dilworth 1971, Weingart 1973), sendo a primeira alternativa mais trabalhosa, e a segunda, mais cara do que o álcool etílico comercial. Din \& STENSON (1982) não recomendam o uso de álcool ou xilol para limpeza dos pêlos, prévia à elaboração de impressões cuticulares sobre cola branca escolar, mas não explicam o motivo.

\section{Preparação de lâminas de impressões cuticulares}

A cola branca escolar forneceu boas impressões nos tempos de secagem de 15 e 30 minutos. Em cinco minutos, a cola não havia secado o suficiente para ser comprimida e, em tempos superiores a 30 minutos, havia secado demasiadamente para que a impressão da cutícula ficasse registrada. A durabilidade das lâminas foi baixa porque a cola não aderiu bem depois de seca, destacando-se com facilidade. Além disso, em longo prazo, nas lâminas guardadas em caixas porta-lâminas de madeira foi observada a hidratação da cola e conseqüente alteração da forma da impressão cuticular. Din \& STENSON (1982) apontam para a facilidade de aquisição e manuseio da cola branca escolar para impressões, contudo, também alertam para sua desvantagem, dizendo que a cola é solúvel em água e a umidade do ar pode rehidratá-la e interferir na forma da impressão, sendo necessário o acondicionamento das lâminas em dessecador.

O esmalte para unhas apresentou os melhores resultados com o tempo de secagem de 15 minutos antes da impressão, pois após 30 minutos, o esmalte já está muito seco e rígido impedindo que as escamas cuticulares tenham sua forma impressa com o detalhamento necessário. Nos tempos testados, inferiores a 15 minutos, o esmalte está muito úmido e adere ao pedaço de madeira revestido utilizado na compressão.

O grampo em "C" foi mais difícil de manusear, a superfície de contato com a lâmina é menor e a pressão exercida é menos homogênea, resultando em impressões melhores no local da pressão do que em outros pontos da lâmina. Com a utilização da morsa com braços retangulares que acompanham aproximadamente a forma e o tamanho das lâminas de microscopia óptica foi possível obter impressões cuticulares mais homogêneas ao longo da lâmina, além de poder ser fixada à bancada de trabalho facilitando seu manuseio.

O método que forneceu os melhores resultados para a retirada dos pêlos do esmalte foi o de passar a ponta do dedo sobre a impressão totalmente seca. A utilização da pinça de ponta fina deve ser evitada porque, por mais cuidado que se tenha no seu manuseio, danifica a parte da impressão onde encosta.

A utilização de esmalte para unhas na obtenção de impressões cuticulares de pêlos de mamíferos foi proposta pela primeira vez por Khmelevskaya (1965), adaptada por WeINGarT (1973) e em seguida utilizada por TwIGg (1975) e por CHARvet \& Keller (1989). O método agora proposto é semelhante ao de Weingart (1973), entretanto há algumas diferenças importantes: (a) segundo Weingart (1973), o tempo de secagem do es-

Revista Brasileira de Zoologia 23 (1): 274-278, março 2006 
malte para unhas na lâmina, antes da colocação do pêlo e prensagem, é de apenas 10 minutos, o que para o esmalte utilizado neste estudo e amplamente disponível no mercado é pouco, sendo, portanto, recomendado um tempo de secagem que varie de 15 a 20 minutos. Alguma variação no tempo ideal é tolerada devido a dois fatores ambientais dificilmente controlados, a temperatura e umidade do ambiente; (b) o tipo da prensa utilizada por Weingart (1973) é um grampo em "C", pressionando particularmente um determinado ponto, o que torna a pressão heterogênea sobre a lâmina (mais forte no centro), diferente do proposto aqui: a utilização de uma morsa com braços retangulares que pressionam homogeneamente toda a lâmina; (c) a retirada do pêlo do esmalte após a compressão segundo WeIngart (1973) deve ser feita com pinça, o que é recomendado apenas em último caso, pois as pinças danificam a impressão. Prioridade é dada para a retirada dos pêlos esfregando cuidadosamente com o dedo; (d) segundo WiengarT (1973) uma vez seco o esmalte, a lâmina permanece útil para confecção de impressões por horas. Em contraste, no presente estudo, observou-se que depois de 30 minutos de secagem do esmalte sobre a lâmina, este se torna demasiadamente rígido para permitir uma boa impressão da superfície do pêlo, resultando em impressões fracas e sem detalhes.

Outros métodos de preparo de impressões de escamas cuticulares citados na literatura, em comparação com os métodos aqui testados, revelam-se demasiadamente caros e trabalhosos. Por exemplo, a utilização de uma camada de resinas termoplásticas (Williamson 1951, Petrarco 1986) ou tiras de acetato (BOWYER \& CURRY 1982) implica no aquecimento e resfriamento do material para obtenção do molde, o que requer uma placa de aquecimento com termostato ou um banho-maria, mais etapas de trabalho e mais tempo. As impressões sobre camadas de gelatina em diferentes concentrações (DAY 1966 - 5\%, TEerink 1991 - 10 a 20\%) têm sido utilizadas com sucesso por vários tricólogos, entretanto a descrição do método pelos autores revela que é mais trabalhoso e mais caro. Sua principal vantagem em relação ao revestimento das lâminas com esmalte para unhas é a facilidade de reaproveitamento imediato da lâmina com gelatina para outra impressão através de seu aquecimento em banho-maria.

A desvantagem do método de impressão cuticular aqui proposto, assim como de outros métodos que não utilizam lamínulas para cobrir as impressões, é o fato das impressões cuticulares ficarem expostas à poeira e a agressões mecânicas.

\section{Preparação de lâminas para observação da medula}

Para que a medula possa ser vista com clareza sob incidência da luz do microscópio, é necessária a substituição do pigmento e espaços com ar do seu interior, pelo meio de montagem da lâmina (TEERINK 1991), sem prejuízo da micro estrutura dos pêlos.

Em comparação com os controles de pêlos não tratados, o processamento em hipoclorito de sódio a 90\% não diafanizou os pêlos em qualquer um dos tempos testados. A diafanização em hidróxido de potássio a $2 \%$ foi danosa para a microestrutura da maioria dos pêlos, comprometendo a interpretação dos padrões morfológicos, nos tempos testados iguais ou superiores a 120 minutos. Em tempos menores que 80 minutos, nenhum efeito de clareamento foi observado e, em 180 minutos, o comprometimento da estrutura do pêlo pela ação do hidróxido de potássio a $2 \%$ foi conspícuo e visível macroscopicamente. Resultados obtidos anteriormente, utilizando hidróxido de potássio a $2 \%$ discordam do presente e, segundo o autor, não há um comprometimento da medula do pêlo para tempos de até 120 minutos de ação do agente diafanizador. A diafanização em água oxigenada comercial 30 volumes não danificou a microestrutura dos pêlos (mesmo no tempo máximo testado, 180 minutos) e forneceu um aumento progressivo do clareamento até o tempo de 80 minutos, a partir do qual não houve uma melhora representativa.

Os cortes transversais na região do escudo melhoraram significativamente a visualização da medula no escudo dos pêlos-guarda mais espessos enquanto que, para os pêlos mais delgados (morcegos, maioria dos roedores e marsupiais), mostraram-se desnecessários, quando comparados com os controles de pêlos não secionados. Um procedimento semelhante de seção dos pêlos é indicado também por TeERINk (1991), o qual realiza múltiplos cortes ao longo de todo o pêlo e determina que, previamente aos cortes, os pêlos devem ser colados à lâmina com cola para papel, evitando o deslocamento dos fragmentos após a seção. Aqui o número de cortes sugeridos é pequeno e estão localizados somente no escudo, portanto não há necessidade de colar os pêlos à lâmina visto que a ordem dos fragmentos é identificável. Charvet \& Keller (1989) não cortam os pêlos e citam que a diafanização com água oxigenada amoniacada é opcional. Isso deve estar relacionado com o fato dos autores terem trabalhado mais intensamente com pêlos de morcegos, finos e delicados. Os resultados aqui obtidos para pêlos finos de roedores e morcegos corroboram os resultados de Charvet \& Keller (1989).

A desvantagem do método de preparação da medula descrito aqui (e de outros métodos descritos na literatura) é que o corte dos pêlos mais espessos para visualização da medula não pode ser evitado.

A montagem das lâminas permanentes com Bálsamo do Canadá sintético, embora recomendada pela maioria dos autores, apresentou as desvantagens do longo tempo de secagem do meio e da coloração amarelada deste. Por outro lado, o Entellan mostrou-se mais vantajoso por ser totalmente transparente e secar rapidamente. Nas lâminas temporárias com utilização de glicerina, foi observado um melhor preenchimento dos espaços contendo ar no interior dos pêlos, os quais são indesejados devido à refringência da luz do microscópio nas bolhas de ar. Embora a quantidade de meio utilizada não tenha sido testada, os melhores resultados foram observados com a menor quantidade de meio necessária à montagem da lâmina. 


\section{CONCLUSÕES}

Vários métodos para estudo da medula e cutícula dos pêlos dos mamíferos já foram desenvolvidos e aperfeiçoados por tricólogos em outros países, cada qual produzindo bons resultados e com suas vantagens e desvantagens. O método selecionado no presente estudo está descrito de forma objetiva no Anexo I e tem o diferencial e principal objetivo de ter execução prática simples e de baixo custo, além de incluir reagentes e equipamentos de fácil aquisição e manipulação, permitindo inclusive sua aplicação durante trabalhos de campo.

\section{AGRADECIMENTOS}

À Sandra Bos Mikich por toda a ajuda na idealização do método apresentado nesse trabalho e leitura do manuscrito. A Nilton C. Cáceres pela criteriosa revisão do manuscrito e sugestões importantes. A Liliani M. Tiepolo pela revisão das citações bibliográficas. À Mülleriana: Sociedade Fritz Müller de Ciências Naturais e ao Instituto de Pesquisas Cananéia (IPeC) pelo apoio institucional. Às instituições brasileiras financiadoras dessa pesquisa, CAPES e CNPq.

\section{REFERÊNCIAS BIBLIOGRÁFICAS}

Bowyer, R.T. \& K.D. CurRy. 1982. Use of a roller press to obtain cuticular impresions of guard hairs on acetate strips. Journal of Mammalogy, Lawrence, 64: 531-532.

Carter, B.C. \& T.G. Dillworth. 1971. A simple technique for revealing the surface pattern of hair. American Midland Naturalist, Notre Dame, 85: 260-262.

Charvet, C. \& A. Keller. 1989. Une méthode douce d'identification des mammifères: la structure fine des poils. Le Rhinolophe, Genebra, 6: 19-25.

Dagnall, J.L.; J.G. Duckett \& J. Gurnell. 1995. A simple negative staining technique for the identification of mammal hairs. Journal of Zoology, London, 237: 670-675.

DAY, M.G. 1966. Identification of hair and feather remains in the gut and feaces of stoats and weasels. Journal of Zoology, London, 148: 201-217.

Din, N.A. \& G.B. STENSON. 1982. A repid method of making hair impressions for microscopy study. Pakistan Journal of Zoology, Lahore, 14: 101-103.

KhmelevsKaya, N.V. 1965. Structure of the hair cuticle, its variability and significance for taxonomy. Osterreeichische Zoologische Zeitschrift, Viena, 44: 1064-1074.

Koonz, C.H. \& E.J. Stradine. 1945. A rapid and simple method for revealing the surface pattern of hair. Transactions of the American Microscopical Society, Lawrence, 64: 63-64.

OLI, M.K. 1993. A key for the identification of the hair of mammals of a snow leopard (Panthera uncia) habitat in
Nepal. Journal of Zoology, London, 231: 71-93.

Petrarco, N. 1986. The replication of hair cuticle scale patterns in Meltmounts. Microscope, London, 34: 341-345.

SHORT, H.L. 1978. Analysis of cuticular scales on hairs using the scanning electron microscope. Journal of Mammalogy, Lawrence, 59: 261-268.

TeERINK, B.J. 1991. Hair of west european mammals: atlas and identification. Cambridge, Cambridge University Press, 224p.

TwIGG, G.I. 1975. Techniques in mammalogy. Mammal Review, Oxford, 5: 71-82.

WeINGART, E.L. 1973. A simple technique for revealing hair scale patterns. American Midland Naturalist, Notre Dame, 90: 508-509.

WiLliamson, V.H.H. 1951. Determination of hairs by impression. Journal of Mammalogy, Lawrence, 32: 80-84.

Anexo I. Descrição objetiva do método recomendado.

a) Colete, diretamente com os dedos, um pequeno tufo de pêlos da região de intersecção da linha mediana com a linha da cintura escapular no dorso de espécimes ou retire pêlos de fezes, conteúdos gastrintestinais, regurgitados, dispositivos coletores de pêlos, locais de ocorrências forenses, sítios zooarqueológicos e sítios paleontológicos;

b) separe os pêlos-guarda, com bulbo e ápice;

c) lave os pêlos-guarda em álcool comercial e seque em papel absorvente;

d) sobre uma lâmina de vidro limpa espalhe uma fina camada de esmalte incolor para unhas e deixe secar 15 a 20 minutos;

e) coloque os pêlos-guarda sobre o esmalte;

f) coloque a lâmina contendo os pêlos sobre um pedaço de madeira e cubra com outro revestido com fita adesiva transparente formando um sanduíche;

g) pressione o conjunto com morsa ou prensa de braços retangulares;

h) abra a morsa e separe a lâmina com os pêlos do resto do conjunto;

i) deixe o esmalte secar totalmente, em torno de 30 minutos;

j) retire os pêlos através da extremidade distal esfregando gentilmente com a ponta do dedo;

k) guarde as lâminas de impressões cuticulares protegidas da poeira;

I) coloque os pêlos retirados em água oxigenada cremosa 30 volumes, comercial, de uso cosmético por 80 minutos. Pêlos espessos devem ser cortados no escudo uma a três vezes para essa etapa;

$\mathrm{m}$ ) lave os pêlos em água e seque em papel absorvente;

n) monte as lâminas permanentes, com meio de montagem sintético transparente e lamínula; ou lâminas temporárias, com água ou glicerina e lamínula.

Recebido em 18.III.2005; aceito em 06.III.2006.

Revista Brasileira de Zoologia 23 (1): 274-278, março 2006 